\title{
Using Online Forums to Promote Collaborative Learning in Introductory Programming Courses
}

\section{Viera Michaličková}

Department of Informatics, Constantine the Philosopher University in Nitra, Slovakia.

\begin{abstract}
The asynchronous online discussion can enrich learning experience in many ways, even in classroom or blended learning scenarios. It is quite challenging to design an effective online discussion. The presented study draws on the action research strategy. After observing and analyzing students' learning problems in introductory programming courses, we came up with intervention of the online collaborative activity to guide students during their individual studying at home in a more regulative manner. The main goal was to involve students in active learning and strengthen the feel of being a friendly community member. Students were producing sample test questions/tasks for others, and then using products of their classmates for their own learning. The intervention was evaluated deeply using both, qualitative and quantitative methods. This reflection implied that the activity's design was appropriate and the impact on students' learning process was positive. We found the constructivist features of the activity essential as for its effectiveness. The learning scenario described in this paper provides a verified framework for designing similar collaborative activities suitable mainly for problem-oriented areas of study, e. g. in science or engineering education.
\end{abstract}

Keywords: Online forums; collaborative learning; programming; action research. 


\section{Introduction}

An asynchronous online discussion can enrich learning experience in many ways, even in classroom or blended learning scenarios. Besides the community building aspect, the online environment gives students more time to think about the topic; motivates students to interact with others (to learn from others); enables students to use their own, less formal language; makes it easier for introvert or slower students to present themselves as active and valuable members of the group.

It is quite challenging to design an effective online discussion. In (Schellens \& Valcke, 2005), the researchers investigated question, whether working in asynchronous discussion forums fosters knowledge construction. Garrison (2007) explored the issues emerging from research on social, cognitive, and teaching presence in an online community of inquiry. Shaw (2013) examined the relationships among group size, participation, and learning performance factors when learning a programming language in a computer-supported collaborative learning context. In (Abawajy \& Kim, 2001), a taxonomy of online forums was suggested. The authors distinct 3 types of online forums:

The auxiliary forums represent optional, open, self-directed, unstructured discussion in which the learner-to-learner interaction prevails. The teacher responds to students' posts from time to time, in order to keep discussion threads alive and relevant or to support students with learning difficulties. In programming courses, our students are active in online forums dedicated to homework assignments. These forums are appreciated especially by novice programmers, who seek for help from their more advanced colleagues.

The hybrid forums are used to enhance or mediate collaborative learning activities. The participation is often compulsory and assessed. Topics and deadlines are set by the lecturer. In programming courses, we use such online forums quite frequently: for short warmups (during lab sessions), team competitions, projects presentations or peer assessment of solutions. In (Lovázsová \& Palmárová, 2012), an activity based on competitive online collaboration suitable for courses on computer programming was described. Students were posting their solutions of problems (programs) in an online forum. Various behavioral patterns of participants were recognized after analyzing students' visible and invisible presence within the online environment. In (Michaličková \& Lovászová, 2014), students were creating a glossary of new terms and programming statements and sharing essays on programming topics with classmates. Both activities were intended to foster students' higher order thinking skills. In this paper, we present a constructivist and collaborative learning activity realized through online forum. It was designed in order to facilitate student's learning when studying for the final exam.

The embedded forums are typical for distance courses, including MOOCs. In general, online forums are considered a primary means of interaction among learners and instructors. 
Though, Onah et al. (2017) doubted that forums are effective means of promoting engagement and learning. They compared two delivery modes of forum participation. Results indicated that forum use overall is low and that tutor-moderation may close down participants' discussion, while peer-support forums fail to offer adequate support.

\section{Collaborative learning through an asynchronous online forum}

\subsection{Research strategy}

The presented study draws on the action research strategy. Action research was introduced by Kurt Lewin in the 1940s and later adopted and applied by many other educational researchers, also in programming courses (Talib et al., 2017). The theory and practice of action research comprise one or more iterations (cycles) with consecutive phases of planning, acting, observing, and reflecting. As pointed out in (Cohen et al., 2007), the action research can be cast into two simple stages: a diagnostic stage in which problems are analyzed, and hypotheses developed; and a therapeutic stage in which the hypotheses are tested by a consciously directed intervention or experiment in situ. The action research works on and tries to solve real problems of everyday practice. It is often collaborative, seeks causes and tries to work on those causes. The solutions (interventions) are planned, implemented, and evaluated by the practitioners themselves.

\subsection{The background context}

The suggested collaborative activity was designed and examined within an introductory programming course taught to in-service teachers studying informatics in order to extend their qualification. There were 19 students enrolled in this course (13 women and 6 men), all of them were novices to programming. The course is focused on fundamental concepts and structures in Python (input and output, variables, data types, conditional statements, cycles, random numbers, tkinter for drawing purposes) and takes one semester. As in many other introductory programming courses, students find the subject difficult, mainly because of its abstract, dynamic, and creative nature. During face-to-face lectures and laboratory exercises, we prefer constructivist and inquiry-based learning activities. Students solve lots of problems on their own (or guided by a teacher) and are encouraged to perform experiments or discuss in groups. We use LMS Moodle (Moodle.org, 2021) for all e-learning activities. The final exam is realized using the Moodle's Test module.

\subsection{The diagnostic stage}

Our research was launched by noticing (also in other courses on programming taught at our university), that many students are afraid of their final exams and feel rather isolated and stressed while studying at home individually. Although students, who were successful in 
hands-on programming assignments during the whole semester, express the lack of confidence after seeing a sample test for the first time. While analyzing data logged by the Moodle system during previous years, we found out, that most students use textual materials for reviewing the course's content and almost all of them try to solve the sample tests. Even multiple attempts are common, though the correct answers are provided immediately after the very first attempt is finished. We always evaluate the exam results with each student separately in order to identify causes of the errors made and explain the correct solutions. It turned out repeatedly, that many students tend to memorize sample questions and correct answers. While solving the exam test, such students have difficulties to recognize analogies, do not apply their knowledge effectively and are more likely to fail.

\subsection{The therapeutic stage}

To help students to overcome the reported learning problems, we planned and implemented two interventions, one after another. During the first cycle preceding the actual study (with other 13 students attending the same course at that time), we focused on taking a sample test together with students in order to demonstrate an expert's way of thinking as well as some problem-solving strategies potentially useful for the upcoming exam test. Though students appreciated the activity a lot, the informal post-exam interviews as well the test results' analysis showed that most students may need some additional distance guidance to achieve better results.

\subsubsection{Planning an intervention}

During the second cycle, we tried to supplement the previous intervention with such an online activity that would guide students during their individual studying at home in a more regulative manner. The main goal was to involve students in active learning and strengthen the feel of being a friendly community member. Students were instructed to produce sample test questions/tasks for others, and then use products of their classmates for their own learning. We believed that such a social constructivist approach would be effective. To provide some extrinsic motivation for students' participation, best questions published by students were promised to be included into the bank of test questions and so could be used also during the real exam.

\subsubsection{Implementing the intervention}

Students were familiar with online forums, as we use them quite frequently. The settings were made in the Forum module to avoid students from copying ideas of others (in Moodle, the Questions and Answers discussion forum allows one to read the discussions' content only after contributing himself/herself first). After the very last lesson, the online forum was opened for contributing over the period of 2,5 weeks (18 days). There were 5 topics chosen for students and sample contributions were provided. The topics were selected so students 
could contribute in a creative way. After finishing the online activity, students took their final exam. The timeline in Figure 1 shows the collaborative activity's progress:

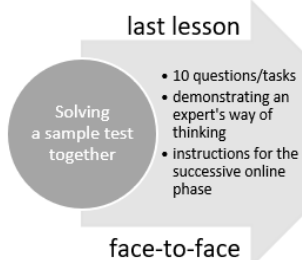

face-to-face

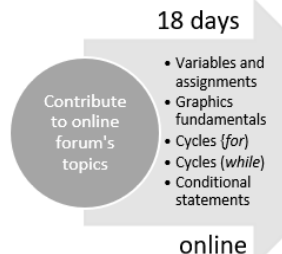

online

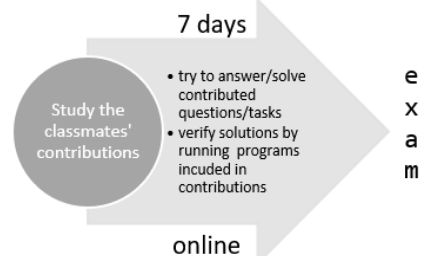

online

Figure 1. Three phases of the collaborative learning activity.

\subsubsection{Evaluating the intervention}

The 17 out of 19 students participated in the online forum actively, 2 students did not access the forum at all (due to personal reasons, the activity was not compulsory). Every participant contributed to every topic and published 5 questions/tasks. The final collection included 85 students' contributions and 15 contributions added by their teacher (as samples and to cover two other topics from the course's content).

Table 1. The quality of students' contributions.

\begin{tabular}{lccc}
\hline Topic & $\begin{array}{c}\text { Number of } \\
\text { contributions }\end{array}$ & $\begin{array}{c}\text { Average } \\
\text { quality } \\
\text { score }\end{array}$ & $\begin{array}{c}\text { Average } \\
\text { exam } \\
\text { score }\end{array}$ \\
\hline Variables and assignments & 17 & 1.82 & 2.65 \\
Graphics fundamentals & 17 & 1.88 & 1.94 \\
Cycles (for) & 17 & 1.41 & 2.82 \\
Cycles (while) & 17 & 1.41 & 2.82 \\
Conditional statements & 17 & 1.35 & 3.00 \\
\hline
\end{tabular}

In Table 1, results of the products' analysis are summarized (but not to present any correlations). The quality of contributions was judged and coded with integers $(0=$ sample was misunderstood, so the related contribution was inappropriate, $1=$ contribution provided an analogy of the sample, 2 = contribution modified the sample in a more creative way). During exam, students were rather successful in answering all types of questions as their average scores were mostly over 2.6 (out of the maximum 3 points per question). The first topic provided students opportunity to use various operators and multiple variables of different types. In graphics-oriented questions, students tried to surprise their colleagues with funny and nice graphical outputs. The contributions concerned with remaining topics on cycles and conditions were adhering to a common template in most cases. In general, quality 
of students' products was satisfactory to be included in a shared collection and used as a study material.

Within the post-exam short interviews, we asked every student to reflect her/his home study activities pursued over the previous weeks. All 17 students (active participants) considered the collaborative learning activity based on using the online forum beneficial. The logs' analysis revealed some details about students' online behavior. The Moodle system monitors all interactions of students within an online forum. For our purposes, only discussion views and post creations were needed to count. Figure 2 depicts the number of logs on individual days during the contributing period (days 1-18) as well as the following study period (days 19-25).

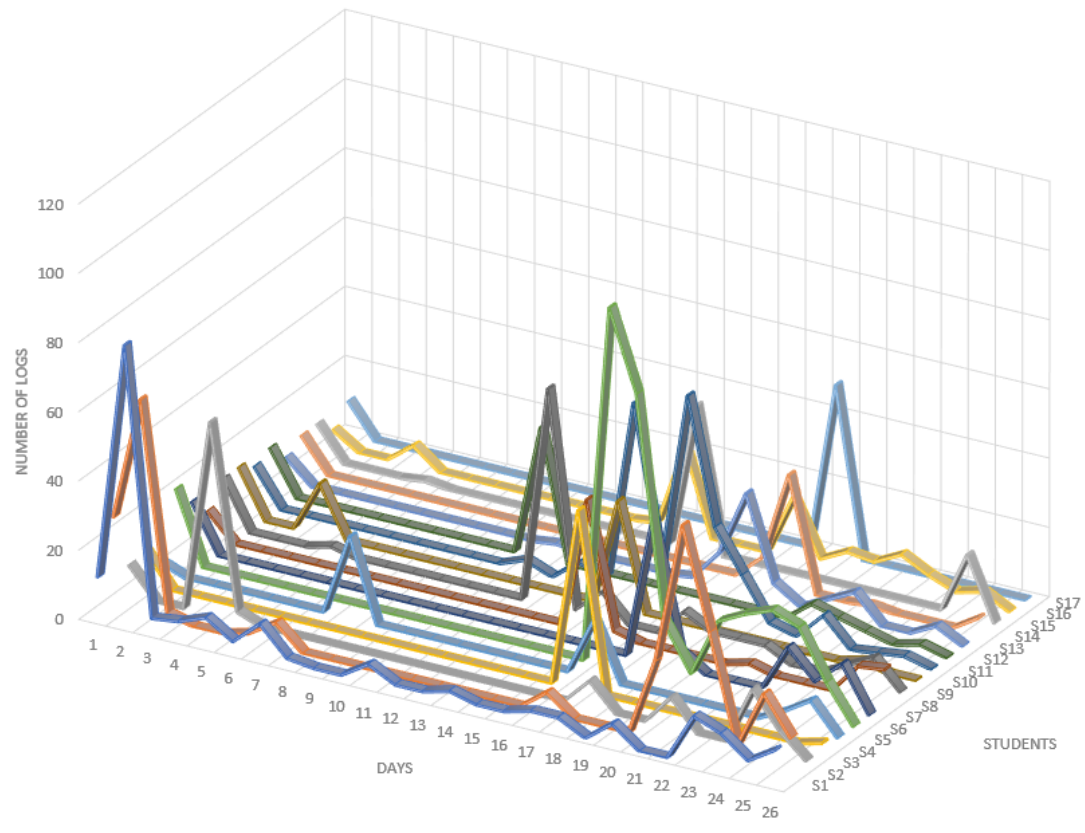

Figure 2. Students' online behavior throughout the online phases.

The activity of students accelerated in both phases during the very last days (11 participants contributed to all topics during one session on a single day, 5 participants needed 2 days, 1 participant published his contributions during a 3-day period). To confirm students' interest in contributions of others, we also checked their returns to forums' topics after completing their contributing phase. On average, 8.29 additional sessions were identified, which implies that students did use the material for study purposes. Students were also asked to describe the process of creating and using the common product verbally. Their responses confirmed our hypothesis. While preparing a contribution, one had to think of a problem, consider the proper notation and verify the intended result using the Python's interpreter (most students 
were running their pieces of code repeatedly before publishing the final version). While studying contributions of others, students were verifying solutions the same way.

The overall results of the exam test were satisfactory (slightly but not significantly better than in previous years or in other courses), the average score reached 22.47 out of 30 . As the main goal of the suggested intervention was to provide students with assistance and foster motivation, we found the intervention effective. To support this conclusion, we state some of the participants' reflections expressed during the post-exam interviews:

- S1: "The collection of questions we created was great, I will archive it and use later with my own students. I was checking the forum almost every day."

- S3: "I spent much time with preparing the question on graphics. But some questions were simple for me, I did not need to solve everything."

- S5: "The topics on cycles were most important for me. I have finally learned how to trace the variables' values on paper."

- S6: "Seeing others' activity was motivation for me to participate actively. My contributions were rather minimalistic, but without publishing, I would not see contents of the collection."

- S12: "Some questions were alike, so I skipped them. I solved all of the problems on variables and cycles though."

- S13: "The sample contributions were helpful. First, I thought I would just change the numbers, but it was quite challenging to prepare something original."

- S16: "This was a very good idea. I felt like I am doing something meaningful."

- S17: "Topics were ok, but some contributions were not formatted well, so I had to copy the notation to my Python editor first to understand what is going on."

\section{Conclusion}

After observing students' learning problems, we came up with intervention of the online collaborative activity. The intervention was evaluated deeply using both, qualitative and quantitative methods. The main criterion for concluding the intervention's effectiveness was whether there would be a positive shift in students' learning process while studying at home. Students found the activity as being beneficial for them. The analysis of logs and contributions of students documented their real involvement well. To create and solve new instances of test questions/tasks, the application of higher-order thinking skills was needed.

The learning scenario described in this paper provides a verified framework for designing similar collaborative activities. It is applicable mainly in problem-oriented areas of study (e. g. in natural sciences or engineering education). In our study, the group of collaborating students was small. Number of students is critical as the huge number of questions or tasks 
could be overwhelming. Some students underestimated the formal aspect of their work and did not refine contributions' format after pasting their source code into the forum's embedded editor. We recommend teachers to train the "rules of posting" with students practically before starting the contributing phase, so they could realize the differences better. The collection of questions/tasks prepared by students was used also later, in a course on didactics, where students discussed the quality of contributions in order to cultivate their critical thinking.

This research was supported by project KEGA 018UMB-4/2020.

\section{References}

Abawajy, J., Kim, T.-h. (2001). Online Learning Environment: Taxonomy of Asynchronous Online Discussion Forums. T.-h. Kim et al. (Eds.): Software Engineering, Business Continuity and Education, CCIS 257. Berlin Heidelberg: Springer-Verlag, pp. 706-714

Cohen, L., Manion, L., \& Morrison, K. (2007). Research Methods in Education. London: Routledge. ISBN 978-0-415-36878-0

Garrison, D. R. (2007). Online Community of Inquiry Review: Social, Cognitive, and Teaching Presence Issues. Journal of Asynchronous Learning Networks, Volume 11, Issue 1, pp. 61-72

Lovászová, G., Palmárová, V. (2012). Promoting Active Learning Through Problem-based Discussion Forums. DIVAI 2012. 9th International Scientific Conference on Distance Learning in Applied Informatics : Conference Proceedings, p. 203-212. ISBN 978-80558-0092-9

Michaličková, V., Lovászová, G. (2014). Fostering Higher-Order Thinking Skills within an Online Learning Environment. DIVAI 2014 : 10th International Scientific Conference on Distance Learning in Applied Informatics. Conference proceedings. p. 411-420. ISBN 978-80-7478-497-2

Onah, D. F., Sinclair, J. E., \& Boyatt, R. (2014). Exploring the use of MOOC discussion forums. Proceedings of London International Conference on Education, p. 1-4. Retrieved from: http://wrap.warwick.ac.uk/65549/

Schellens, T., Valcke, M. (2005) Collaborative learning in asynchronous discussion groups: What about the impact on cognitive processing? Computers in Human Behavior 21(6), p. 957-975. doi: 10.1016/j.chb.2004.02.025

Shaw, R.-S. (2013). The relationships among group size, participation, and performance of programming language learning supported with online forums. Computers \& Education, Volume 62, p. 196-207. doi: 10.1016/j.compedu.2012.11.001

Talib, N., Yassin, S. F. M, \& Nasir, M. K. M. (2017). Teaching and Learning Computer Programming Using Gamification and Observation through Action Research. International Journal of Academic Research in Progressive Education and Development 6(3): 1-11. doi: 10.6007/IJARPED/v6-i3/3045 